\title{
KAJIAN HACCP (Hazard Analysis and Critical Control Point) PROSES PEMBUATAN SNACK BAR BERBASIS PISANG (Musa paradisiaca)
}

\section{THE STUDY OF HACCP (HAZARD ANAL YSIS AND CRITICAL CONTROL POINT) CREATION PROCESS OF BANANA (Musa Paradisiaca) SNACK BARS}

\author{
Imam Achmad Fauzi Krisnandar ${ }^{1}$, Diki Nanang Surahman ${ }^{2}$, Riyanti Ekafitri ${ }^{2}$, \\ Wisnu Cahyadi ${ }^{1}$, Nur Kartika Indah Mayasti ${ }^{2}$
}

\author{
${ }^{1}$ Teknologi Pangan, Fakultas Teknik Universitas Pasundan, \\ Jalan Dr. Setiabudhi No. 193, Gegerkalong, Sukasari, Kota Bandung, 40153, Jawa Barat \\ ${ }^{2}$ Pusat Penelitian Teknologi Tepat Guna, Lembang Ilmu Pengetahuan Indonesia (P2TTG- \\ LIPI), Jalan K.S. Tubun No.5, Kota Subang, 41213, Jawa Barat, Indonesia.
}

Email : imam.163020206@mail.unpas.ac.id

Diterima: 20-08-2021

Direvisi: 25-11-2021

Disetujui: 29-12-2021

\begin{abstract}
ABSTRAK
Snack bar adalah makanan ringan dengan bentuk batang yang terbuat dari berbagai bahan dasar seperti serealia dan kacang-kacangan. Konsumsi makanan fungsional saat ini mulai diminati karena mengandung zat yang bermanfaat bagi tubuh. Salah satu pemanfaatan produk snack bar yaitu menggunakan buah pisang. Pilot plant P2TTG LIPI Subang merupakan unit pengolahan buah pisang menjadi snack bar. Proses produksi snack bar membutuhkan penerapan sistem HACCP untuk meningkatkan kualitas dan keamanan produk. Oleh karena itu, kajian sistem HACCP ini penting untuk dilaksanakan. Berdasarkan rekomendasi Standar Nasional Indonesia, kajian identifikasi HACCP dilaksanakan dengan menggunakan panduan penyusunan rencana HACCP. Berdasarkan hasil kajian didapat bahwa CCP pada bahan adalah telur, puree pisang ambon, susu full cream bubuk, dan margarin. Sedangkan CCP pada proses pengolahan adalah pemanggangan I, pemanggangan II, dan pendinginan. Seluruh CCP ini perlu pengawasan optimal terutama pada: penanganan bahan baku, pengendalian kebersihan operator dan memastikan kecukupan panas serta waktu saat proses pemanggangan snack bar berbasis pisang. Efektifitas penerapan HACCP ini dapat diketahui melalui proses verifikasi. Penerapan HACCP diharapkan dapat meningkatkan kualitas dan keamanan produk snack bar berbasis pisang.
\end{abstract}

Kata kunci: HACCP, pisang, snack bar

\section{ABSTRACT}

Snack bars are snacks with stick shapes made from various essential ingredients such as cereals and nuts. Consumption of functional foods is currently starting to be in demand because it contains beneficial substances to the body. One of the uses of snack bar products is using bananas. The pilot plant P2TTG-LIPI Subang is a unit for processing bananas into snack bars. The snack bar production process requires implementing a HACCP system to improve product quality and safety. Therefore, this study of the HACCP system is vital to carry out. Based on the Indonesian National Standard recommendations, the HACCP identification study was carried out using the HACCP planning guidelines. The study results found that the CCP in the ingredients were eggs, Ambon banana puree, full cream milk powder, and margarine. In contrast, the CCP in the processing is roasting I, roasting II, and cooling. All of these CCPs need optimal supervision, especially on handling raw materials, controlling operator hygiene, and ensuring adequate heat and time during the banana-based snack bar baking process. The effectiveness of HACCP implementation can be known through the verification process. The implementation of HACCP is expected to improve the quality and safety of banana-based snack bar products.

Keywords: banana, HACCP, snack bar 


\section{PENDAHULUAN}

nack bar adalah makanan ringan dengan bentuk batang yang terbuat dari
berbagai bahan seperti serealia dan kacang-kacangan. Konsumsi makanan
fungsional saat ini mulai diminati karena ekonomis, praktis, fleksibel, serta mengandung zat yang bermanfaat bagi tubuh (Saparinto and Hidayati, 2006). Produk snack bar dapat dibuat dari pisang. Sarifudin et al. (2015), menyatakan bahwa pemanfaatan buah pisang yang dijadikan tepung memiliki potensi yang baik untuk digunakan bahan fungsionalnya seperti serat dan kalium cukup tinggi. Tepung pisang dari buah yang masih mentah mempunyai kandungan total pati yang tinggi $(73,4 \%)$, serta kandungan pati resisten yang besar $(17,5 \%)$ dan kadar serat makanan yang bisa mencapai $(14,5 \%)$ sehingga tepung ini menjadi alternatif pembuatan produk roti dan snack bebas gluten cukup potensial untuk dikembangkan (Bello-Pérez et al., 2005).

Snack bar berbasis pisang ini berpotensi dikembangkan menjadi komoditas industri pangan. Jaminan keamanan produk pangan merupakan faktor penting yang harus diperhatikan. Tidak adanya sistem penjamin keamanan pangan mengakibatkan timbulnya penurunan kualitas produk yang dihasilkan. Cemaran pada produk akan mengakibatkan efek keracunan makanan. Keracunan makanan timbul akibat adanya bahan makanan yang tidak aman disebabkan karena kesalahan dalam penanganan dan pengolahan pangan (Hariyadi and Dewanti, 2009). Pada proses pengolahan snack bar, perlu adanya penanganan dalam mencegah terjadinya insiden keracunan pangan, salah satunya dengan menerapkan sistem HACCP yaitu Hazard Analysis Critical Control Point. HACCP telah banyak digunakan sebagai sistem keamanan pangan yang efektif dalam meminimalkan resiko bahaya keamanan pangan. Penerapan HACCP akan mengkaji titik-titik bahaya dari penggunaan bahan baku dalam pembuatan snack bar pisang dan proses pengolahannya. Sistem keamanan yang efektif adalah sistem yang dapat diterapkan, dengan melaksanakan analisis bahaya terhadap proses dan fasilitas produksi sehingga dapat membantu pihak produsen untuk mengendalikan kemungkinan terjadinya resiko (Fakhmi, Rahman and Riawati, 2013). Kajian ini bertujuan untuk mengidentifikasi titik-titik bahaya yang terdapat pada bahan baku yang digunakan dan tahapan proses pengolahan snack bar berbasis pisang dengan menggunakan delapan langkah, empat prinsip HACCP sehingga proses produksi dapat dikendalikan dan menghasilkan produk yang bermutu.

\section{METODE PENELITIAN}

Kajian ini dilakukan pada tahun 2020 terhadap pilot plant snack bar berbasis pisang di UPT Pilot Plant (P2TTG) LIPI, Subang, Jawa Barat. Menurut CAC (Codex Alimentarius Commission), konsep perencanaan HACCP terdiri atas 12 tahap termasuk 7 prinsip dasar HACCP. Prinsip ini diadopsi oleh Indonesia yang tertuang dalam Standar Nasional Indonesia (SNI) nomor 01-4852-1998 tentang Sistem Analisis Bahaya dan Pengendalian Titik-Titik Kritis (HACCP) beserta pedoman penerapannya yaitu Pedoman BSN 1004/1999 (BSN, 1998). Tahapan penelitian penerapan sistem HACCP dilakukan sebagai berikut: menyusun tim HACCP (tahap 1), deskripsi produk dilengkapi dengan pengujian kadar air metode gravimetri (BSN, 2015a), analisa tekstur dengan texture analyzer, uji mikrobiologi kapang khamir (BSN, 2015b), analisa Eschericia coli dan salmonela (BSN, 2006), analisa Staphylococcus aureus (BSN, 2008) (tahap 2), identifikasi tujuan penggunaan produk (tahap 3), membuat diagram alir (tahap 4), verifikasi diagram alir (tahap 5), membuat daftar potensi yang berbahaya, melakukan analisis terhadap bahaya dan menenentukan tindakan pencegahan (prinsip 1), menentukan critical control points (CCPS) (prinsip 2), serta menetapkan ambang batas kritis pada setiap CCP (prinsip 3). 


\section{HASIL DAN PEMBAHASAN}

\section{Deskripsi Produk}

Snack bar adalah makanan padat dengan bentuk batang yang berbahan dasar tepung dengan tambahan bahan kering melalui proses baking yang dijadikan satu dengan bantuan binder. Bahan kering yang dimaksud dapat berupa serealia, kacang-kacangan, dan buahbuahan kering (Gillies, 1974). Adapun deskripsi produk snack bar berbasis pisang yang diproduksi oleh Binaan Usaha Kecil Menengah (BUKM-Subang) dapat dilihat pada Tabel 1.

Tabel 1. Deskripsi Produk

\begin{tabular}{ll}
\hline \multicolumn{1}{c}{ Kriteria } & \multicolumn{1}{c}{ Keterangan } \\
\hline Nama Produk & Snack bar berbasis pisang \\
Nama Merek Dagang & Pro Barz \\
Komposisi & Telur, Gula Pasir, SP (soluble powder), Puree Pisang Ambon, \\
& Susu Full cream bubuk, Tepung Pisang Nangka, Pati Kentang, \\
& Garam, BP (Baking powder), Margarin, Mikronutrien (Vitamin dan \\
& Mineral) \\
Pengemas Primer & Aluminium Foil \\
Pengemas Sekunder & Dus Karton \\
Masa Kadaluarsa & 10 Bulan \\
Kondisi Penyimpanan & Suhu Kamar/270 C \\
Cara penyiapan konsumsi & Dikonsumsi langsung \\
Metode Distribusi & Suhu Kamar/270 C \\
Rencana penggunaan & Snack Sehat \\
Hasil Pengujian: & $3,87 \%$ \\
$>$ Kadar Air & \\
$>$ Texture Analyzer: & $9223,14 \mathrm{~g}$ \\
-Kekerasan & $18,32 \mathrm{~mm}$ \\
Cemaran Mikroba: & \\
- Escherichia coli & $<3,0 \mathrm{APM} / \mathrm{g}$ \\
- Coliform & $<3,0 \mathrm{APM} / \mathrm{g}$ \\
- Staphylococcus aureus & $5 \times 10^{\wedge} 1 \mathrm{CFU} / \mathrm{g}$ \\
- Kapang dan khamir & $8,75 \times 10^{\wedge} 1 \mathrm{CFU} / \mathrm{g}$ \\
\hline
\end{tabular}

\section{Diagram Alir Proses Pembuatan Snack Bar Berbasis Pisang}

Diagram alir yang dibuat berdasarkan pengamatan pada proses produksi snack bar dimulai dari bahan diterima hingga menjadi produk yang siap disajikan kepada konsumen. Diagram direncanakan dan dilakukan verifikasi pada kondisi proses sebenarnya di lapangan, diagram alir dapat dilihat pada Gambar 1. 


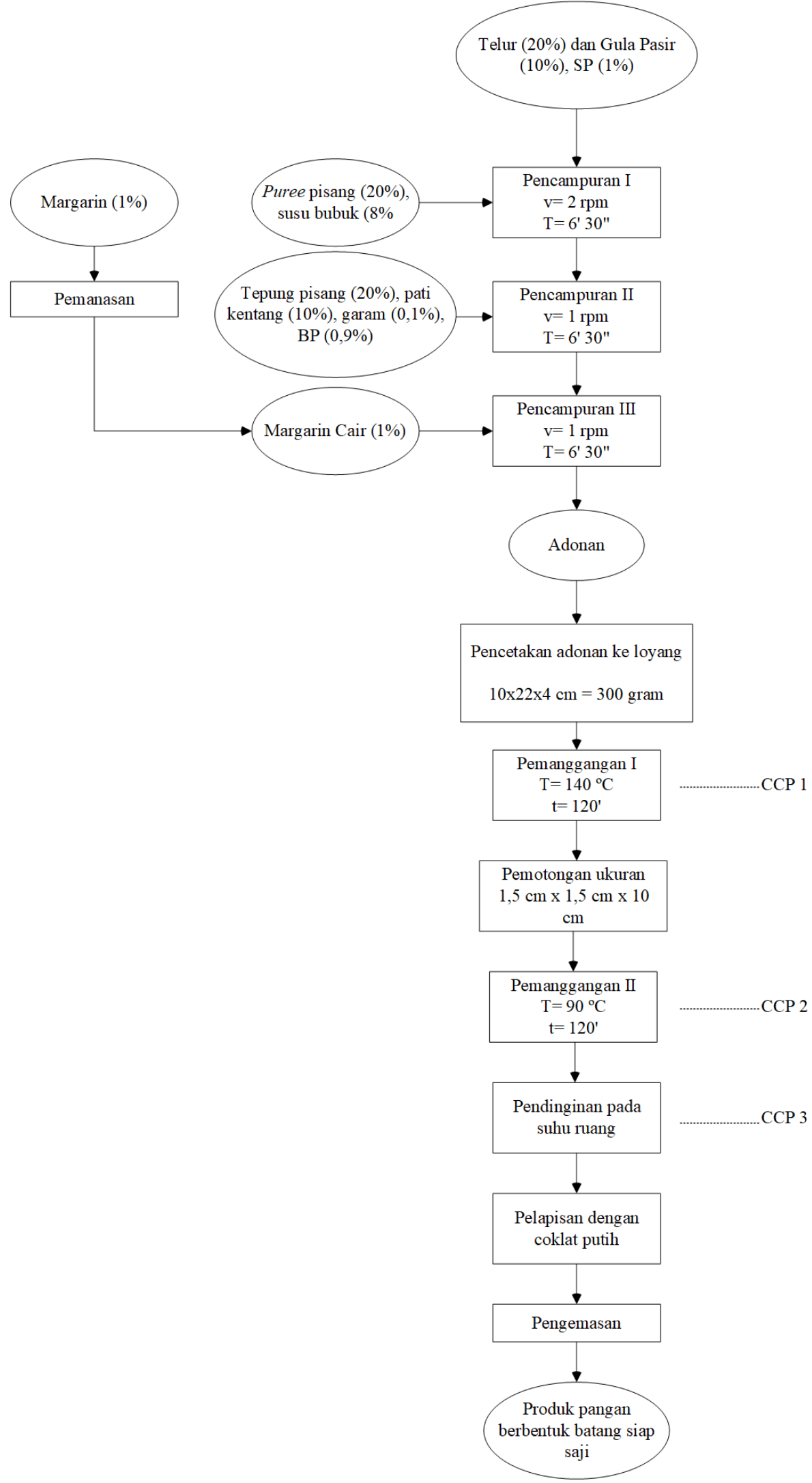

Gambar 1. Diagram alir dan verifikasi diagram alir proses produksi pembuatan snack bar berbasis pisang 
Tabel 2. Identifikasi Bahaya Bahan Baku

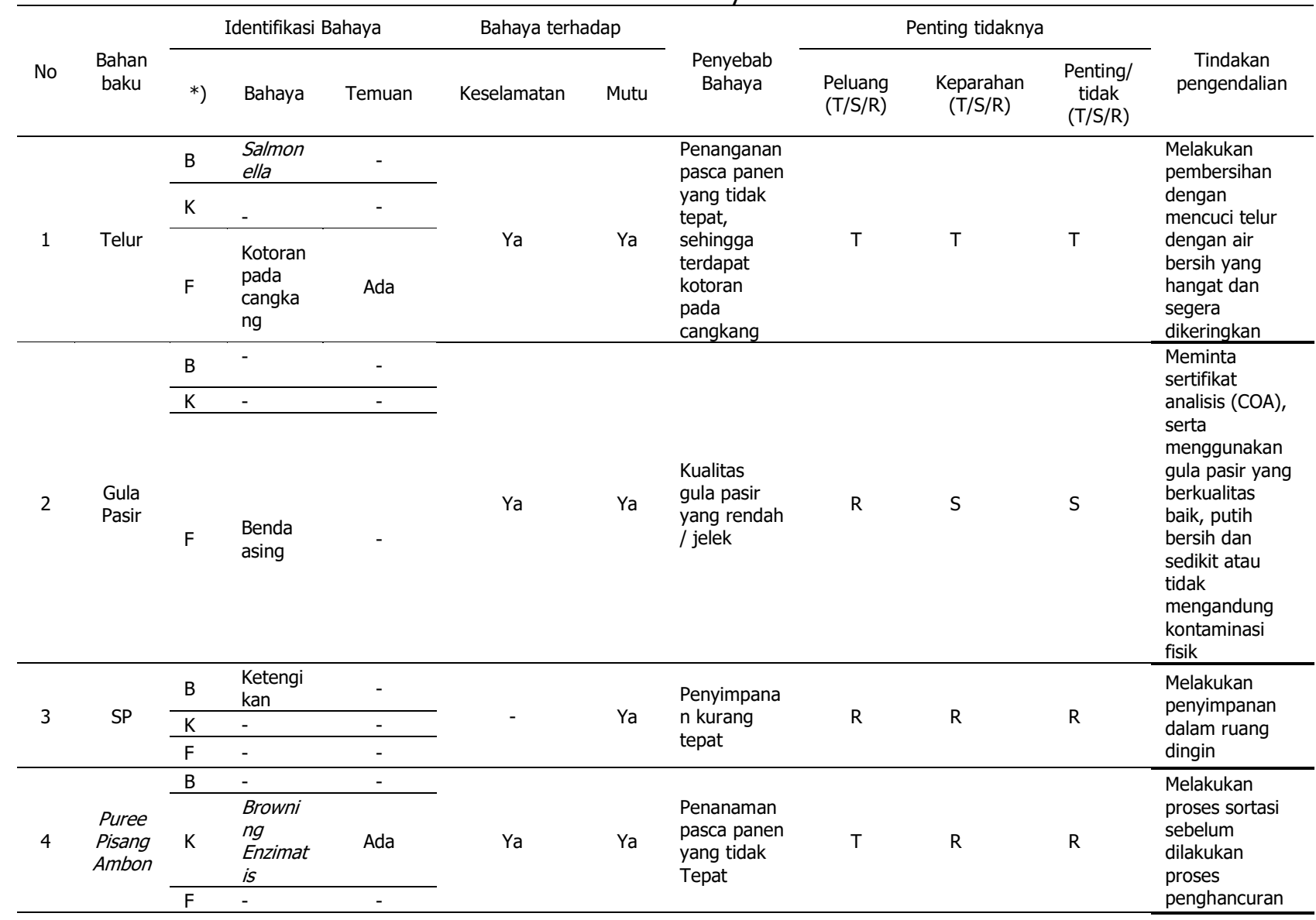


Tabel 2. Identifikasi Bahaya Bahan Baku (Lanjutan)

\begin{tabular}{|c|c|c|c|c|c|c|c|c|c|c|c|}
\hline \multirow[b]{2}{*}{ No } & \multirow[b]{2}{*}{ Bahan baku } & \multicolumn{3}{|c|}{ Identifikasi Bahaya } & \multicolumn{2}{|c|}{ Bahaya terhadap } & \multirow[b]{2}{*}{$\begin{array}{c}\text { Penyebab } \\
\text { Bahaya }\end{array}$} & \multicolumn{3}{|c|}{ Penting tidaknya } & \multirow[b]{2}{*}{$\begin{array}{c}\text { Tindakan } \\
\text { pengendalian }\end{array}$} \\
\hline & & * & Bahaya & Temuan & Keselamatan & Mutu & & $\begin{array}{l}\text { Peluang } \\
(T / S / R)\end{array}$ & $\begin{array}{l}\text { Keparaha } \\
\text { n (T/S/R) }\end{array}$ & $\begin{array}{l}\text { Penting } \\
\text { / tidak } \\
(\mathrm{T} / \mathrm{S} / \mathrm{R}) \\
\end{array}$ & \\
\hline \multirow{3}{*}{5} & \multirow{3}{*}{$\begin{array}{c}\text { Susu Full } \\
\text { Cream } \\
\text { Bubuk }\end{array}$} & B & - & - & \multirow{3}{*}{ Ya } & \multirow{3}{*}{ Ya } & \multirow{3}{*}{$\begin{array}{l}\text { Sumber } \\
\text { bahan baku } \\
\text { tidak } \\
\text { terkontrol, } \\
\text { Penyimpanan } \\
\text { tidak tepat }\end{array}$} & \multirow{3}{*}{ T } & \multirow{3}{*}{$\mathrm{T}$} & \multirow{3}{*}{$\mathrm{T}$} & \multirow{3}{*}{$\begin{array}{l}\text { Meminta } \\
\text { sertifikat } \\
\text { analisis } \\
(\mathrm{COA}) \text {, } \\
\text { Menyimpan } \\
\text { bahan baku } \\
\text { tertutup } \\
\text { rapat } \\
\end{array}$} \\
\hline & & K & Melamin & - & & & & & & & \\
\hline & & $F$ & - & - & & & & & & & \\
\hline \multirow{3}{*}{6} & \multirow{3}{*}{$\begin{array}{l}\text { Tepung } \\
\text { pisang } \\
\text { nangka }\end{array}$} & B & - & - & \multirow{3}{*}{ Ya } & \multirow{3}{*}{ Ya } & \multirow{3}{*}{$\begin{array}{l}\text { Penyimpanan } \\
\text { tidak tepat }\end{array}$} & \multirow{3}{*}{$\mathrm{R}$} & \multirow{3}{*}{$\mathrm{R}$} & \multirow{3}{*}{$\mathrm{R}$} & \multirow{3}{*}{$\begin{array}{l}\text { Menyimpan } \\
\text { bahan baku } \\
\text { tertutup } \\
\text { rapat }\end{array}$} \\
\hline & & K & & - & & & & & & & \\
\hline & & $\mathrm{F}$ & $\begin{array}{l}\text { Benda } \\
\text { asing }\end{array}$ & - & & & & & & & \\
\hline \multirow{3}{*}{7} & \multirow{3}{*}{$\begin{array}{c}\text { Pati } \\
\text { kentang }\end{array}$} & B & - & - & \multirow{3}{*}{ Ya } & \multirow{3}{*}{ Ya } & \multirow{3}{*}{$\begin{array}{l}\text { Penyimpanan } \\
\text { tidak tepat }\end{array}$} & \multirow{3}{*}{$\mathrm{R}$} & \multirow{3}{*}{$\mathrm{R}$} & \multirow{3}{*}{$\mathrm{R}$} & \\
\hline & & K & $\begin{array}{l}\text { Keteng } \\
\text { ikan }\end{array}$ & - & & & & & & & $\begin{array}{l}\text { sertifikat } \\
\text { analisis }\end{array}$ \\
\hline & & $\mathrm{F}$ & - & - & & & & & & & \\
\hline & & B & - & - & & & & & & & \\
\hline 8 & Garam & K & - & - & - & Ya & - & $\mathrm{R}$ & $\mathrm{R}$ & $\mathrm{R}$ & - \\
\hline & & $\mathrm{F}$ & $\begin{array}{l}\text { Benda } \\
\text { asing }\end{array}$ & - & & & & & & & \\
\hline & & B & - & - & & & Kualitas & & & & Meminta \\
\hline 9 & $\begin{array}{l}\text { Baking } \\
\text { Powder }\end{array}$ & K & $\begin{array}{l}\text { Oksida } \\
\text { si } \\
\end{array}$ & - & - & Ya & $\begin{array}{l}\text { baking } \\
\text { powder yang }\end{array}$ & $\mathrm{R}$ & $\mathrm{R}$ & $\mathrm{R}$ & $\begin{array}{l}\text { sertifikat } \\
\text { analisis }\end{array}$ \\
\hline & & $\mathrm{F}$ & - & - & & & rendah & & & & $(\mathrm{COA})$ \\
\hline & & B & - & - & & & & & & & Melakukan \\
\hline 10 & Margarin & K & $\begin{array}{l}\text { Keteng } \\
\text { ikan }\end{array}$ & - & Ya & Ya & $\begin{array}{l}\text { Penyimpanan } \\
\text { tidak tepat }\end{array}$ & $\mathrm{T}$ & $\mathrm{T}$ & $\mathrm{T}$ & $\begin{array}{l}\text { penyimpana } \\
\mathrm{n} \text { dalam }\end{array}$ \\
\hline & & $\mathrm{F}$ & - & - & & & & & & & ruang dingin \\
\hline
\end{tabular}

Keterangan: $B=$ biologis, $K=$ kimiawi, $F=$ fisik, $T=$ tinggi, $S=$ sedang, dan $R=$ rendah 


\section{Identifikasi Bahaya Untuk Bahan Baku}

Proses pengolahan snack bar menggunakan bahan baku buah pisang Ambon, telur, susu full cream bubuk, tepung pisang nangka, pati kentang, margarin dan bahan tambahan pangan lain, yaitu SP sebagai pengemulsi, garam berfungsi untuk mempertahankan kelembaban, gula pasir sebagai pemanis, dan baking powder sebagai bahan pengembang adonan (Saparinto and Hidayati, 2006). Bahaya-bahaya yang teridentifikasi pada bahan baku seperti disajikan pada Tabel 2.

Bahan baku pertama yaitu pisang Ambon. Cemaran yang dapat diidentifikasi yaitu pencoklatan, pencoklatan dapat menyebabkan penurunan kualitas selama penanganan pasca panen dan pengolahan. Pencoklatan pada buah pisang dapat menyebabkan perubahan yang merusak penampilan dan sifat organoleptic (Otwell dan Iyengar, 1992). Tindakan pengendalian yang dapat dilakukan. Melakukan penyimpanan dengan membungkus bonggol pisang supaya tahan lebih lama (Muchtadi and Ayustaningwarno, 2010). Bahan baku kedua adalah telur, telur ini diperoleh dari supplier telur yang terdapat di pasar tradisional Subang. Cemaran yang dapat diidentifikasi pada telur yaitu mikroba patogenik yaitu kelompok bakteri Coliform seperti Salmonella sp dan Escherichia coli, sedangkan kapang yang biasanya mencemari telur adalah Penicillium sp (Soekarto, 2013). Menurut Muchtadi and Ayustaningwarno (2010), salah satu cara untuk mempertahankan mutu telur dengan menyimpannya pada suhu rendah berkisar antara $12,8-15,6{ }^{\circ} \mathrm{C}$, hal tersebut dapat menekan penguapan air dari telur dengan kelembaban relatif $70 \%$.

Bahan baku ketiga adalah susu full cream bubuk. Susu dapat tercemar melamin akibat dari penyimpanan yang tidak tepat, yakni ketika susu disimpan dalam wadah yang kurang rapat. Cemaran ini pun dapat terjadi ketika bahan baku susu yang digunakan tidak terkontrol asal muasalnya. Menurut Ibáñez et al. (2009), konsumsi susu yang mengandung melamin akan berdampak pada kerusakan ginjal. Untuk mencegah resiko kontaminan dari melamin yaitu memilih supplier yang tepat dengan meminta COA (Certificate of Analysis) produk. Bahan baku keempat yaitu tepung pisang nangka. Cemaran yang diidentifikasi pada bahan baku ini adalah cemaran fisik berupa debu, dan benda asing. Untuk meminimalisir adanya cemaran fisik dapat dilakukan dengan menggunakan tepung pisang nangka yang berkualitas baik, sedikit, atau tidak mengandung kotoran terutama kontaminan fisik dengan cara memilih supplier yang tepat dengan meminta COA (Certificate of Analysis) produk.

Bahan baku kelima yaitu pati kentang. Cemaran yang diidentifikasi pada bahan baku ini adalah cemaran kimia berupa ketengikan. Untuk meminimalisir kerusakan agar tahan dalam waktu lebih lama, dapat dilakukan dengan cara menyimpan didalam ruang dingin serta menutup kemasan jika telah digunakan (Hermiati, et al., 2013). Bahan baku keenam yaitu margarin. Cemaran yang diidentifikasi pada bahan baku ini adalah cemaran kimia berupa ketengikan. Pada suhu kamar, oksigen dari udara dapat mengoksidasi asam lemak tidak jenuh yang terdapat dalam margarin. Oleh karena itu bahan baku yang berlemak harus disimpan dalam wadah tertutup dan diletakkan di ruang dingin untuk meminimalisir terjadinya kerusakan sehingga bahan baku dapat disimpan lebih lama (Hermiati, et al, 2013).

Bahan baku selanjutnya adalah gula pasir. Cemaran yang diidentifikasi pada bahan baku ini adalah cemaran fisik yang dapat berupa debu. Cemaran tersebut dapat diminimalisir dengan menggunakan gula pasir yang berkualitas baik, sedikit, atau tidak mengandung kotoran terutama kontaminasi fisik. Minimalisir cemaran juga dapat dilakukan dengan tindakan pengayakan atau penyaringan sebelum penggunaan gula pasir pada poses pengkondisian (Surahman dan Ekafitri, 2014). Bahan tambahan pangan yang digunakan pada pembuatan snack bar antara lain SP, garam, dan baking powder. Penggunaan SP, garam, dan baking powder harus memiliki kualitas yang baik dengan memperhatikan batas maksimal dalam penggunaan BTP. Izin dalam penggunaan SP untuk pengembang maksimal 481 ppm, penggunaan garam maksimal 331 ppm, dan penggunaan baking powder maksimal 501 ppm (BPOM, 2019). 
Tabel 3. Identifikasi Bahaya Proses Pengolahan

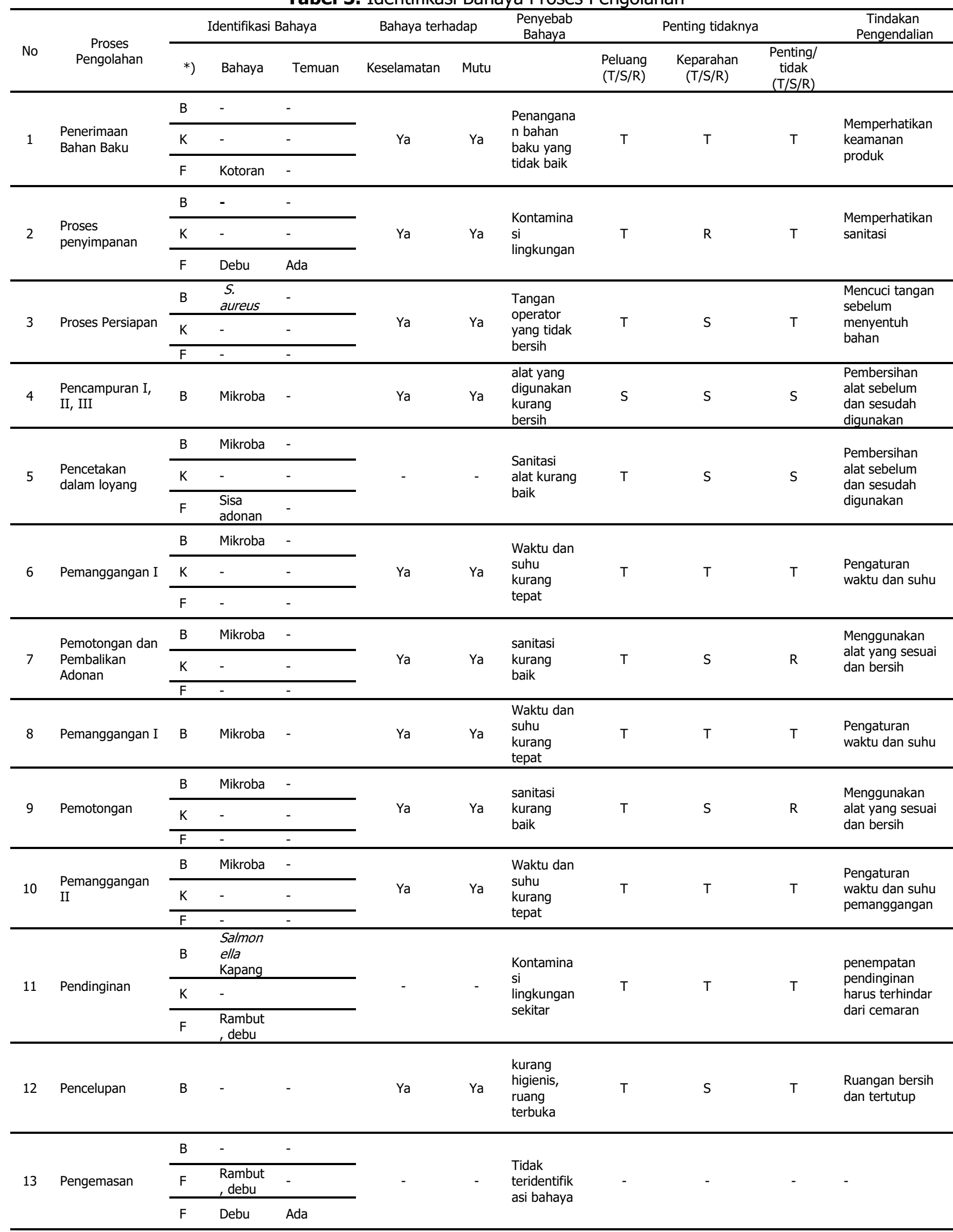


Tabel 4. Matriks Critical Control Point (CCP) Pada Proses Pengolahan Snack Bar Berbasis Pisang

\begin{tabular}{|c|c|c|c|c|c|c|c|c|c|c|}
\hline \multirow{2}{*}{ No } & \multirow{2}{*}{ Tahap } & \multirow{2}{*}{$\begin{array}{l}\text { CCP } \\
\text { No }\end{array}$} & \multirow{2}{*}{ Jenis Bahaya } & \multirow{2}{*}{$\begin{array}{c}\text { Batas kritis } \\
\text { (prinsip 3) }\end{array}$} & \multicolumn{4}{|c|}{$\begin{array}{l}\text { Monitoring } \\
\text { (prinsip 4) }\end{array}$} & \multirow{2}{*}{$\begin{array}{l}\text { Tindakan } \\
\text { koreksi } \\
\text { (prinsip 5) }\end{array}$} & \multirow{2}{*}{$\begin{array}{c}\text { Catatan/ } \\
\text { dokumentasi }\end{array}$} \\
\hline & & & & & Metoda & Frekuensi & Objek & Personal & & \\
\hline 1 & $\begin{array}{l}\text { Pemanggangan } \\
\text { I dan II }\end{array}$ & 1 & $\begin{array}{l}\text { Pertumbuhan } \\
\text { mikroba }\end{array}$ & $\begin{array}{l}\text { Suhu dan } \\
\text { waktu } \\
\text { pemanasan } \\
\text { harus tepat } \\
\left(\mathrm{T}=150^{\circ} \mathrm{C} \mathrm{t}=\right. \\
15-30 \text { menit), } \\
\text { tidak } \\
\text { ditemukan } \\
\text { bakteri } \\
\text { termofilik }\end{array}$ & $\begin{array}{l}\text { Pengecekan } \\
\text { suhu dan lama } \\
\text { pemanggangan }\end{array}$ & $\begin{array}{l}\text { Setiap } \\
\text { proses }\end{array}$ & Adonan & QC & $\begin{array}{l}\text { Kalibrasi oven } \\
\text { secara berkala }\end{array}$ & $\begin{array}{l}\text { Log book } \\
\text { proses, } \\
\text { thermometer, } \\
\text { action log }\end{array}$ \\
\hline 2 & Pendinginan & 2 & $\begin{array}{l}\text { Pertumbuhan } \\
\text { Kapang }\end{array}$ & $\begin{array}{l}\text { Menurunkan } \\
a_{w}<0,62\end{array}$ & $\begin{array}{l}\text { Pengecekan } \\
\text { kelembaban, } \\
\text { menyimpan } \\
\text { dalam wadah } \\
\text { tertutup }\end{array}$ & $\begin{array}{l}\text { Setiap } \\
\text { proses }\end{array}$ & $\begin{array}{c}\text { Hasil } \\
\text { Adonan }\end{array}$ & $\mathrm{QC}$ & $\begin{array}{l}\text { Membuat } \\
\text { ruang khusus }\end{array}$ & $\begin{array}{l}\text { Log book } \\
\text { proses, } \\
\text { log book } \\
\text { pendinginan }\end{array}$ \\
\hline
\end{tabular}

\section{Penentuan CCP Untuk Pengendalian (Prinsip 2)}

Identifikasi bahaya proses yang dihasilkan pada proses pembuatan snack bar berbasis pisang dapat dilihat pada Tabel 3. Untuk penentuan Critical Control Point (CCP), penetapan ambang batas kritis, tindakan monitoring (pemantauan), serta tindakan koreksi dapat dilihat pada Tabel 4. Proses pertama dalam pembuatan snack bar adalah penerimaan bahan baku. Kegiatan ini berfungsi untuk mencegah kontaminasi pada bahan baku sebelum dilakukan proses pengolahan dengan cara sortasi. Bahaya yang dapat diidentifikasi cemaran fisik berupa pisang yang busuk, bulu, retak dan kotoran pada telur. Proses sortasi juga dilakukan guna memisahkan bahan baku telur atau pisang yang sudah rusak dan tidak layak untuk diolah. Tindakan pencegahan yang dapat dilakukan yaitu dengan penanganan bahan baku yang baik dengan mengawasi kualitas dan keamanan bahan baku selama proses penerimaan serta menjaga kebersihan operator.

Tahapan kedua setelah penerimaan bahan baku adalah penyimpanan bahan baku. Bahaya yang dapat diidentifikasi adalah adanya kemungkinan kontaminasi fisik, terutama dari lingkungan seperti debu. Debu dapat masuk ke area penyimpanan melalui bahan makanan, pembungkusnya, pakaian, dan alat pelindung diri. Tindakan pencegahan yang dapat dilakukan yaitu dengan mengawasi sanitasi lingkungan dan operator agar selalu higienis, serta melakukan pembersihan secara berkala.

Tahapan ketiga yaitu penyiapan bahan baku. Bahaya yang teridentifikasi pada tahapan ini adalah bahaya mikrobiologi yaitu adanya bakteri $S$. aureus. Bakteri ini dapat berasal dari penanganan bahan baku yang tidak baik atau adanya kontaminasi dari operator. Menurut Surahman dan Ekafitri (2014b), manusia yang sehat saja merupakan sumber mikroba, bakteri Streptococcus tidak hanya dapat berasal dari kotoran, namun dapat juga berasal dari organ tubuh manusia lainnya seperti mulut, hidung, tenggorokan, dan kulit. Tindakan pengendalian yang dapat dilakukan adalah dengan penanganan bahan baku yang baik, serta senantiasa mengawasi higienitas operator selama menyiapkan bahan baku.

Setelah bahan baku disiapkan, selanjutnya dilakukan proses pencampuran I, II, dan III. Tahapan ini berfungsi agar memperoleh adonan yang baik yaitu merata/homogen, mudah dicetak (Muchtadi dan Sugiyono, 2013). Hasil temuan selama proses pengamatan pada proses ini, adonan tidak tercampur merata akibat waktu pencampuran yang tidak ditentukan, jika waktu pencampuran lebih lama maka akan merusak gluten, sehingga retak ketika dipanggang. Hasil temuan lain saat proses pencetakan dalam loyang yaitu bahaya kontaminasi akibat pembersihan kurang sempurna dan kurang higienis. Tindakan pengendalian yang dapat dilakukan adalah melakukan pencucian peralatan secara berkala baik sebelum maupun sesudah proses produksi, serta dengan menggunakan alkohol $70 \%$. 
Bahaya yang muncul dalam proses pemanggangan I (CCP 1) terutama berkaitan dengan pertumbuhan bakteri karena masalah suhu. Tindakan pencegahannya adalah dengan mengkalibrasi pemanggang atau oven secara berkala. Setelah dilakukan pemanggangan I, dilakukan pemotongan pada produk. Tahapan ini memiliki resiko bahaya mikrobiologi yang diakibatkan oleh penggunaan alat pemotong atau pisau yang kurang higienis. Tindakan pengendaliannya yaitu dengan menggunakan alat pemotong yang bersih dan terbuat dari logam stainless steel sehingga tidak berkarat (Surahman dan Ekafitri, 2014c). Tahap selanjutnya adalah pemanggangan II (CCP 2). Bahaya yang diidentifikasi pada tahapan ini adalah cemaran mikrobiologi, yakni pertumbuhan mikroba karena masalah suhu yang tidak tepat. Tindakan pencegahannya adalah dengan mengkalibrasi pemanggang secara berkala.

Setelah itu, dilakukan pendinginan (CCP 3). Bahaya pada tahap ini adalah adanya kontaminasi fisik dan mikrobiologi karena proses pendinginan produk dilakukan di tempat yang terbuka dan tidak tertutup dengan baik dalam ruang pengolahan. Tindakan pencegahannya yaitu dengan menempatkan proses pendinginan di ruangan khusus guna menghindari kontaminasi (Surahman dan Ekafitri, 2014d). Tahapan selanjutnya adalah pencelupan. Bahaya yang diidentifikasi pada tahap ini yaitu cemaran fisik berupa rambut, debu. Debu dapat masuk ke daerah penyimpanan dapat melalui bahan makanan, pembungkusnya, pakaian, alat pelindung diri. Tindakan pencegahan yaitu dengan mengawasi sanitasi lingkungan dan operator agar selalu higienis.

Berdasarkan uraian diatas dapat disimpulkan bahwa pada tahapan proses pemanggangan I, pemanggangan II, dan pendinginan dapat dikategorikan sebagai Critical Control Poin (CCP). Setiap tahapan proses yang termasuk CCP dapat dilihat pada Tabel 4.

\section{KESIMPULAN}

Hasil kajian HACCP terhadap produksi snack bar berbasis pisang BUKM (Binaan Usaha Kecil Menengah-Subang) di UPT Pilot Plant (P2TTG) LIPI Subang menunjukkan bahwa CCP pada bahan baku adalah telur, puree pisang Ambon, dan susu full cream bubuk. CCP pada proses pengolahan yaitu pada pemanggangan I, pemanggangan II, dan pendinginan. Penerapan sistem HACCP yang baik dapat dilakukan dengan: Penanganan bahan baku secara hygienis, penerapan sanitasi pekerja serta lingkungan kerja, pengkalibrasian alat pemanggang secara berkala, dan penggunaan ruang khusus dalam setiap proses pengolahan. Penerapan sistem HACCP ini diharapkan dapat meningkatkan kualitas dan keamanan produk snack bar berbasis pisang.

\section{DAFTAR PUSTAKA}

Badan Pengawas Obat dan Makanan. (2019). Peraturan Badan Pengawas Obat dan Makanan tentang Bahan Tambahan Pangan. Badan Pengawas Obat dan Makanan Republik Indonesia, pp. 1-10.

Badan Stadarisasi Nasional (BSN). (1998). SNI 01-4852-1998 : Sistem Analisis Bahaya dan Pengendalian Titik Kritis (HACCP) serta Pedoman Penerapannya. BSN : Jakarta

Badan Stadarisasi Nasional (BSN). (2015a). SNI 2354:2015. Cara Uji Kimia-Bagian 2 : Pengujian Kadar Air pada Produk Perikanan. BSN : Jakarta

Badan Stadarisasi Nasional (BSN). (2015b). SNI 2332.7.2:2015. Cara Uji Mikrobiologi-Bagian 7 : Perhitungan Kapang dan Khamir pada Produk Perikanan. BSN: Jakarta

Badan Stadarisasi Nasional (BSN). (2006). SNI 01-2332.1:2006. Cara Uji Mikrobiologi-Bagian 1 : Penentuan coliform dan Escherichia coli pada Produk Perikanan. BSN: Jakarta

Badan Stadarisasi Nasional (BSN). (2008). SNI 2897:2008. Metode Pengujian Cemaran Mikrobia dalam Daging, Telur, dan Susu, serta Hasil Olahannya. BSN: Jakarta

Bello-Pérez, L. A. De Francisco, A., Agama-Acevedo, E., Gutierrez-Meraz, F., García-Suarez, F.J.L.. (2005). Morphological and Molecular Studies of Banana Starch. Food Science and Technology International, 11(5), pp. 367-372. doi: 10.1177/1082013205058409. 
Fakhmi, A., Rahman, A. and Riawati, L. (2013). Desain Sistem Keamanan Pangan Hazard Analysis and Critical Control Point ( HACCP ) Pada Proses Produksi Gula PG. Kebon Agung Malang. Jurnal Rekayasa dan Manajemen Sistem Industri, 2(6), pp. 11681179.

Gillies, M. (1974). Compressed Food Bars. Food Techn. New Jersey: Noyes Data Corp.

Hariyadi, P and Dewanti, R. (2009) 'Petunjuk Sederhana Memproduksi Pangan yang Aman'. Jakarta: PT. Dian Rakyat.

Hermiati., Rusli., Manalu, N. Y., Sinaga, M. S. (2013. 'Ekstrak Daun Sirih Hijau dan Merah Sebagai Antioksidan pada Minyak Kelapa, Jurnal Teknik Kimia USU, 2(1), pp. 37-43. doi: $10.32734 / j t k . v 2 i 1.1425$.

Ibáñez, M., Sancho, J. V. and Hernández, F. (2009). Determination of Melamine in Milkbased Products and Other Food and Beverage Products by Ion-Pair Liquid Chromatography-Tandem Mass Spectrometry, Analytica Chimica Acta, 649 (1), pp. 91-97. doi: 10.1016/j.aca.2009.07.016.

Muchtadi. T. R and Ayustaningwarno, F. (2010) Teknologi Proses Pengolahan Pangan. Bandung: ALFABETA.

Muchtadi, T. R. and Sugiyono (2013). Prinsip Proses dan Teknologi Pangan. Bandung: ALFABETA.

Otwell, W. S. and Iyengar, R. (1992). Inhibition of Enzymatic Browning in Foods and Beverages, Critical Reviews in Food Science and Nutrition, 32(3), pp. 253-273. doi: 10.1080/10408399209527599.

Saparinto, C. and Hidayati, D. (2006) Bahan Tambahan Pangan. Yogyakarta : Kanisius

Sarifudin, A., Ekafitri, R., Surahman, D. N., Putri, S. K. D. F. A. (2015). Pengaruh Penambahan Telur Pada Kandungan Proksimat, Karakteristik Aktivitas Air Bebas (Aw) dan Tekstural Snack Bar Berbasis Pisang (Musa Paradisiaca). Jurnal Agritech, 35(01), p. 1. doi: 10.22146/agritech.9413.

Soekarto, S. T. (2013). Teknologi Penanganan dan Pengolahan Telur. Bandung: ALFABETA.

Surahman, D. N. and Ekafitri, R. (2014). Kajian HACCP (Hazard Analysis And Critical Control Point) Pengolahan Jambu Biji di Pilot Plant Sari Buah UPT. B2PTTG - LIPI Subang. Jurnal Agritech, 34(03), p. 266. doi: 10.22146/agritech.9454. 